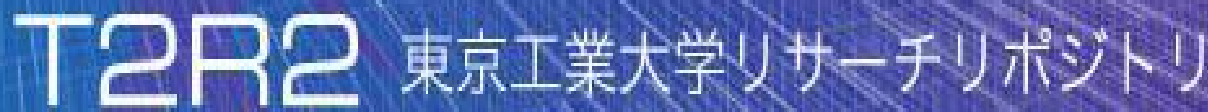

\section{Tokyo Tech Research Repository}

\section{論文 /著書情報 \\ Article /Book Information}

\begin{tabular}{|c|c|}
\hline Title & Tellurite G lass Micro-Superspheres as Broadband Raman Resonator \\
\hline Authors & $\begin{array}{l}\text { Yusuke Arai, Guanshi Q in, Takenobu Suzuki, Yasutake Ohishi, Tetsuji } \\
\text { Yano, Shuichi Shibata }\end{array}$ \\
\hline Citation(English) & SPIE Photonics West 2008, Vol. 6890, No. , pp. 6890-09 \\
\hline$-1---1--1-1$ & - \\
\hline 発行日 /Pub. date & 2008, 1 \\
\hline & \\
\hline DOI & http://dx.doi.org/10.1117/12.763030 \\
\hline 権利情報 /Copyright & $\begin{array}{l}\text { 本著作物の著作権はSociety of Photo-O ptical Instrumentation } \\
\text { Engineersに帰属します。 } \\
\text { Copyright } 2008 \text { Society of Photo-O ptical Instrumentation Engineers. } \\
\text { One print or electronic copy may be made for personal use only. } \\
\text { Systematic reproduction and distribution, duplication of any material in } \\
\text { this paper for a fee or for commercial purposes, or modification of the } \\
\text { content of the paper are prohibited. }\end{array}$ \\
\hline
\end{tabular}




\title{
Tellurite glass micro-superspheres as broadband Raman resonator
}

\author{
Yusuke Arai, Guanshi Qin, Takenobu Suzuki and Yasutake Ohishi ${ }^{a}$, \\ Tetsuji Yano and Shuichi Shibata ${ }^{b}$ \\ ${ }^{a}$ Research Center for Advanced Photon Technology, Toyota Technological Institute, \\ 2-12-1 Hisakata Tempaku-ku, Nagoya 468-8511, Japan; \\ ${ }^{b}$ Tokyo Institute of Technology, 2-12-1 Ookayama Meguroku, Tokyo 152-8550, Japan.
}

\begin{abstract}
Tellurite glass micro-superspheres (Te- $\mu \mathrm{SSs}$ ) were prepared by the surface-tension mold (StM) technique, and their whispering gallery mode (WGM) resonances have been investigated as the first trial to realize an ultra-broadband Raman resonator. Micrometer-sized tellurite glass particles were melted on an optical grade glassy-carbon substrate then cooled to room temperature (StM technique). Resultant Te- $\mu$ SS possesses a super-spherical shape with high optical transparency. The size of the partly truncated area, resulting from the contact surface with the substrate, can be controlled by the composition of the glass and a microsphere with no truncated area was achieved for a glass with $56 \mathrm{TeO}_{2}-3.5 \mathrm{BaO}-10.5 \mathrm{SrO}_{-}-8 \mathrm{Nb}_{2} \mathrm{O}_{5^{-}}$ $4 \mathrm{WO}_{3}-16 \mathrm{P}_{2} \mathrm{O}_{5}$ (TBSN-4W-16P) composition. The TBSN-4W-16P $\mu \mathrm{SS}$ was excited at $532 \mathrm{~nm}$, and the WGM resonance emission attributed to broad Raman scattering of the glass itself was observed. The $Q$ value of the $\mu \mathrm{SS}$ was $\approx 5 \times 10^{3}$. It was confirmed that the prepared $\mu \mathrm{SSs}$ possess a sufficiently spherical shape and acted as an efficient WGM resonator. These results predict that the Te- $\mu \mathrm{SS}$ has potential for a novel broadband Raman laser.
\end{abstract}

Keywords: tellurite glass, whispering gallery mode resonance, broadband Raman resonator, surface tension mold technique

\section{INTRODUCTION}

Broadband amplifiers in near-infrared region are key devices for the future photonic network systems. Many attempts have been made on broadening and flattening of gain spectra of erbium ion-doped fiber amplifiers (EDFA). ${ }^{1-3}$ In addition, much work has been done to expand the usable bandwidth for wavelength division multiplexing (WDM) systems; connecting the several rare-earth-doped fiber amplifiers (RDFA), containing different rare earth ions, in series or in parallel, for instance. Fluoride and heavy metal oxide glasses have been studied as host materials for RDFAs to expand these amplification bandwidth because these glasses have low energy phonons compared with $\mathrm{SiO}_{2}$ glasses and many rare earth ions are optically active in them. ${ }^{1}$ This approach has contributed much to expand the gain bandwidth of rare earth ions, however, there is still a need to explore the materials themselves that have good thermal stability and optical performances. Additionally, the gain bandwidth of each rare-earth ion is limited due to narrow nature of $f-f$ transitions, hence the gain band of several connected RDFAs is still discontinuous. Fiber Raman amplifiers (FRA) have been gathering much attention because the gain bandwidth of FRA is only restricted by the pump wavelength and Raman active modes of the medium itself. ${ }^{4}$ The silica and germanium-doped silica glasses are currently used as Raman gain media in telecommunications industry. However, the FRA based on these glasses have very low Raman gain response and limited usable spectral bandwidth of around $5 \mathrm{THz}$ for single pump excitation. Therefore, research for new materials with enhanced Raman gain coefficients and/or bandwidths has been undertaken by many researchers. ${ }^{5-9}$

Tellurite glasses are a promising candidate for FRAs and lasers ${ }^{10}$ because they have $~ 30$ times higher Raman gain coefficients and much larger Stokes shift than silica glass. ${ }^{5,6}$ It has added advantages, such as: wide transmission window, ${ }^{11}$ good glass stability and durability, ${ }^{10}$ high refractive index, ${ }^{12}$ higher nonlinear optical properties ${ }^{13}$ and relatively low phonon energies.

Recently, we reported a new $\mathrm{TeO}_{2}-\mathrm{BaO}-\mathrm{SrO}-\mathrm{Nb}_{2} \mathrm{O}_{5}$ (TBSN) tellurite glass system to enhance the gain bandwidth of tellurite glasses. ${ }^{7}$ 14-17 The gain bandwidth of TBSN glasses were wider than that of the conventional tellurite glasses, ${ }^{14}$ and the bandwidth was spread by the addition of $\mathrm{WO}_{3}$ and $\mathrm{P}_{2} \mathrm{O}_{5}$ while maintaining higher gain coefficients. ${ }^{16,17}$

Further author information: E-mail: yusukea@toyota-ti.ac.jp, Telephone: +81 52809 1862, Fax: +81 528091869

Optical Components and Materials V, edited by Michel J. F. Digonnet, Shibin Jiang, John W. Glesener, J. Christopher Dries Proc. of SPIE Vol. 6890, 689009, (2008) · 0277-786X/08/\$18 - doi: 10.1117/12.763030 
On the other hand, novel micro-optical cavities are also desirable to realize the all-optical integrated circuit. Of growing the interest among such micro-optical cavities is a whispering-gallery mode (WGM) resonators in a microsphere because of its high quality factor $(Q){ }^{18}$ There have several reports of WGMs in microspheres, and various techniques of preparing microspheres has been developed: melting a tip of a $\mathrm{SiO}_{2}$ fiber with a $\mathrm{CO}_{2}$ laser, ${ }^{18}$ microwave plasma torch, ${ }^{19}$ liquid-liquid phase separation of $\mathrm{BaO}-\mathrm{B}_{2} \mathrm{O}_{3}$ glass, ${ }^{20}$ vibrating orifice technique ${ }^{21,22}$ and so on.

In our previous work, the novel preparation method of micrometer-sized superspheres ( $\mu \mathrm{SS})$ named Surface-tension Mold (StM) technique has been developed. ${ }^{23-27}$ This technique uses the self-organization of glass melts driven by the surface tension of the droplet on the substrate, and $\mu \mathrm{SSs}$ with very smooth spherical surface can be prepared easily. We have confirmed the WGMs from $\mathrm{Eu}_{2} \mathrm{O}_{3}$-doped $\mathrm{Na}_{2} \mathrm{O}-\mathrm{CaO}-\mathrm{SiO}_{2} \mu \mathrm{SSs}$ with a estimated $Q \geq 10^{3}$, under the $514.5 \mathrm{~nm}$ laser excitation. ${ }^{23}$ We have also confirmed the partly truncated area of the $\mu \mathrm{SS}$ which results from contact between the surface and the substrate, can be readily controlled by the composition of the glass. ${ }^{27}$

The $Q$ values of WGM resonances depend on sphericity, surface condition, diameter and refractive index of the microsphere. ${ }^{28}$ The presence of truncated area suppress the $Q$ of the $\mu \mathrm{SS}$. The glasses with lower wettability, i.e. higher surface tension (surface energy), are preferable, because the size of the truncated area depends on the wettability of the glass against the substrate. Therefore, if the tellurite glass $\mu \mathrm{SS}$ is realized, it is be expected to be a high- $Q$ micrometer-sized broadband Raman resonator, because tellurite glasses possess not only high Raman coefficients, but also high refractive indices and high surface energies.

In this report, preparation of tellurite glass $\mu$ SSs and investigation of their optical functionality as broadband Raman resonator are presented.

\section{EXPERIMENTAL}

\subsection{Sample preparation}

All glasses were prepared following a conventional melt-quenching technique using $\mathrm{TeO}_{2}(99.9 \%), \mathrm{BaCO}_{3}(99 \%), \mathrm{SrCO}_{3}$ (99.9\%), $\mathrm{Nb}_{2} \mathrm{O}_{5}(99.9 \%), \mathrm{WO}_{3}(99.9 \%)$, and $\mathrm{P}_{2} \mathrm{O}_{5}(99 \%)$. The prepared compositions are summarized in Table 1. Appropriate amounts of these chemicals were mixed in a zirconia mortar and pestle inside a glove box with a dry nitrogen atmosphere. The mixed powders $(\sim 10 \mathrm{~g})$ were melted in a platinum crucible at $900-1000{ }^{\circ} \mathrm{C}$ for $\sim 20$ min using an electrical furnace with a dry oxy-nitrogen atmosphere. The melt was then quenched onto a preheated copper plate to $\sim 350^{\circ} \mathrm{C}$ and subsequently annealed at this temperature for $\sim 10 \mathrm{~h}$ to release the thermal stresses developed during quenching process. A part of the melt was quenched to room temperature and kept without annealing for thermal analysis.

The bulk glass samples were cut to a thickness of $1-2 \mathrm{~mm}$ and polished to optical quality before subjecting them to the optical measurements. A part of the obtained glass was crushed and classified by using sieves in order to obtain the glass particles with sizes from $32-63 \mu \mathrm{m}$. Then the particles were dispersed on the finely polished glassy carbon (g-carbon) substrate. The particles on g-carbon substrate were heated up to a certain temperature $\left(T_{s}+50 \sim 100^{\circ} \mathrm{C}\right.$ where $T_{s}$ is softening temperature of the glass) and held for $30 \mathrm{~min}$ under the nitrogen atmosphere, and then cooled to the room temperature. The heating rate and cooling rate were $10^{\circ} \mathrm{C} / \mathrm{min}$.

\subsection{Characterization}

Thermal properties of prepared glasses were studied by a differential scanning calorimeter (Rigaku, ThermoPlus DSC 8270). About $50 \mathrm{mg}$ of the finely powdered as-quenched glasses were heated in a platinum pan at a rate of $10^{\circ} \mathrm{C} / \mathrm{min}$ in the $30-900{ }^{\circ} \mathrm{C}$ range. Glass transition temperatures $\left(T_{g}\right)$, softening temperatures $\left(T_{s}\right)$ and first crystallization temperatures $\left(T_{x 1}\right)$ of the glasses were obtained from DSC curves. The $T_{g}$ and $T_{x 1}$ were determined from the tangent intersections of the endothermic peak and the first exothermic peak in the DSC curves, respectively. The $T_{s}$ were obtained from the peak temperatures of the first endothermic peak.

The obtained glass particles were observed by the scanning electron microscope (SEM) and optical microscope (OM) to obtain the particle shape (the sphericity and the contact angle of the truncated part), surface roughness, and the optical transparency. Figure 1 shows the schematic illustration of the glass droplet on a g-carbon substrate. The contact angle $\theta$ was calculated from the SEM images using the equation as follows:

$$
\theta=\arcsin \left(\frac{r}{R}\right)
$$




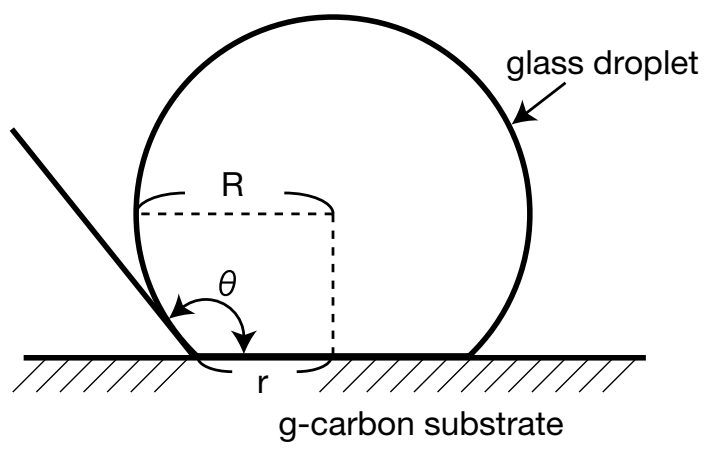

Figure 1. Schematic illustration of the glass droplet on a g-carbon substrate.

where $r$ is a radius of the truncated area and $R$ is a radius of the particle.

The ordinary Raman spectra of the glasses were measured by a Raman spectrometer (JASCO, NRS 2100) in the 25 to $1700 \mathrm{~cm}^{-1}$ range. The samples were excited at $532 \mathrm{~nm}$ with power of $5 \sim 100 \mathrm{~mW}$. The spectrum was recorded in the quasi-back scattered mode with $\mathrm{v} / \mathrm{v}$ polarization. The measured Raman intensities were corrected using the following equation:

$$
I_{\text {corr }}=\frac{v}{\left(v_{0}-v\right)^{4}}\left[1-\exp \left(-\frac{h v}{k T}\right)\right] \times I_{o b s},
$$

where $I_{c o r r}$ is the corrected intensity, $I_{o b s}$ is the measured intensity, $v_{0}$ is the frequency of the excitation light, $v$ is the Raman shift, $h$ is the Planck's constant, and $T$ is the absolute temperature.

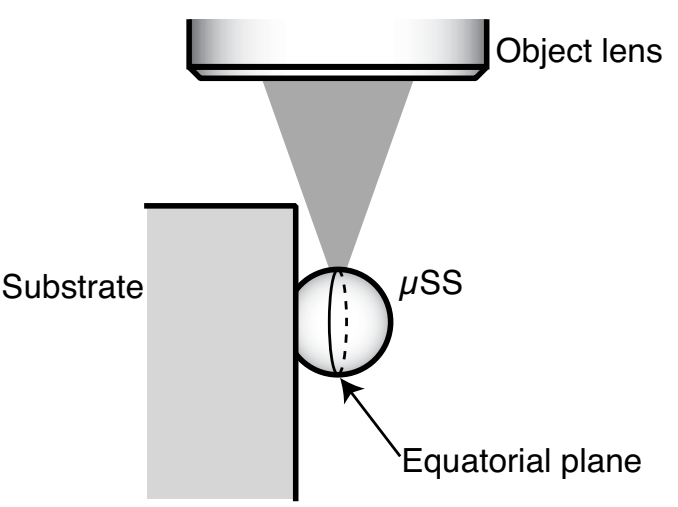

Figure 2. Schematic illustration of the setup of the $\mu \mathrm{SS}$ for emission spectra measurements.

The WGM resonance spectra of the $\mu$ SSs were measured by a microscopic Raman spectrometer (JASCO, NRS 2100) in the $25-1700 \mathrm{~cm}^{-1}$ range. The $\mu \mathrm{SS}$ attached on the substrate was placed on the precision optic liner stage (Newport, ULTRAlign 561D-XYZ). The substrate was set vertically as shown in Fig. 2. The $\mu$ SS was excited at $532 \mathrm{~nm}$ with a power of $5 \sim 100 \mathrm{~mW}$. The spectrum was recorded in the microscopic co-focal mode with $\mathrm{v} / \mathrm{v}$ polarization. The spectral resolution of the monochromator was $1 \mathrm{~cm}^{-1}$. The sizes of the examined $\mu \mathrm{SSs}$ were measured from the captured images by CCD camera equipped in Raman microscope. 


\section{RESULTS AND DISCUSSION}

The glass transition temperature $\left(T_{g}\right)$, softening temperature $\left(T_{s}\right)$ and the first crystallization temperature $\left(T_{x 1}\right)$ of prepared glasses are summarized in Table 1 . The $T_{g}, T_{s}$ and $T_{x 1}$ of TBSN glasses was confirmed to increase due to $\mathrm{WO}_{3}$ and $\mathrm{P}_{2} \mathrm{O}_{5}$ doping. $\Delta T=T_{x 1}-T_{g}$, this indicates the thermal stability of the glass and is also shown in the Table 1 . During the StM process the glass powders are heated up to $T_{s}+50 \sim 100^{\circ} \mathrm{C}$, thus higher thermal stability is desirable. $\Delta T$ increased with increasing $\mathrm{WO}_{3}$ and $\mathrm{P}_{2} \mathrm{O}_{5}$ contents, and the highest $\Delta T=238$ was achieved in TBSN-4W-16P composition.

Table 1. Compositions and thermal properties of the glass samples. $T_{g}, T_{s}$ and $T_{x 1}$ are glass transition temperature, softening temperature and first crystallization temperature of the glass, respectively. $\Delta T=T_{x 1}-T_{g}$ is the thermal stability of the glass.

\begin{tabular}{llcccc}
\hline \hline Name & Glass composition & $T_{g}\left({ }^{\circ} \mathrm{C}\right)$ & $T_{s}\left({ }^{\circ} \mathrm{C}\right)$ & $T_{x 1}\left({ }^{\circ} \mathrm{C}\right)$ & $\Delta T$ \\
\hline TBSN & $78 \mathrm{TeO}_{2}-3.5 \mathrm{BaO}-10.5 \mathrm{SrO}-8 \mathrm{Nb}_{2} \mathrm{O}_{5}$ & 387 & 412 & 471 & 84 \\
TBSN-4W-0P & $74 \mathrm{TeO}_{2}-3.5 \mathrm{BaO}-10.5 \mathrm{SrO}-8 \mathrm{Nb}_{2} \mathrm{O}_{5}-4 \mathrm{WO}_{3}$ & 395 & 427 & 497 & 102 \\
TBSN-8W-0P & $70 \mathrm{TeO}_{2}-3.5 \mathrm{BaO}-10.5 \mathrm{SrO}-8 \mathrm{Nb}_{2} \mathrm{O}_{5}-8 \mathrm{WO}_{3}$ & 404 & 441 & 538 & 134 \\
TBSN-4W-8P & $66 \mathrm{TeO}_{2}-3.5 \mathrm{BaO}-10.5 \mathrm{SrO}-8 \mathrm{Nb}_{2} \mathrm{O}_{5}-4 \mathrm{WO}_{3}-8 \mathrm{P}_{2} \mathrm{O}_{5}$ & 410 & 437 & 602 & 192 \\
TBSN-0W-16P & $62 \mathrm{TeO}_{2}-3.5 \mathrm{BaO}-10.5 \mathrm{SrO}-8 \mathrm{Nb}_{2} \mathrm{O}_{5}-16 \mathrm{P}_{2} \mathrm{O}_{5}$ & 429 & 468 & 642 & 213 \\
TBSN-2W-16P & $60 \mathrm{TeO}_{2}-3.5 \mathrm{BaO}-10.5 \mathrm{SrO}-8 \mathrm{Nb}_{2} \mathrm{O}_{5}-2 \mathrm{WO}_{3}-16 \mathrm{P}_{2} \mathrm{O}_{5}$ & 431 & 471 & 668 & 237 \\
TBSN-4W-16P & $56 \mathrm{TeO}_{2}-3.5 \mathrm{BaO}-10.5 \mathrm{SrO}-8 \mathrm{Nb}_{2} \mathrm{O}_{5}-4 \mathrm{WO}_{3}-16 \mathrm{P}_{2} \mathrm{O}_{5}$ & 437 & 476 & 675 & 238 \\
\hline \hline
\end{tabular}

Figure 3 shows the SEM images of the bottom-side of the obtained glass particles with the diameter of about $35 \mu \mathrm{m}$. All of the glass particles formed superspherical shape as shown in Fig. 3 except for the TBSN-4W-OP composition. Bubbles were observed at the truncated area, which was the contact surface with the g-carbon substrate. The largest bubbles were confirmed in TBSN-4W-0P. The bubbles were not observed at the top-side of the particles, thus these were caused by the reaction between the g-carbon substrate and some gases, which was most likely $\mathrm{O}_{2}$ eliminated from the TBSN glasses. This reactivity decreased with increasing $\mathrm{WO}_{3}$ and $\mathrm{P}_{2} \mathrm{O}_{5}$ contents, hence the surface defects were almost eliminated in TBSN- $x$ W-16P $\mu$ SSs.

Figure 4 shows the dependence of the contact angle $\theta$ on the (a) $\mathrm{P}_{2} \mathrm{O}_{5}$ and (b) $\mathrm{WO}_{3}$ contents. $\theta$ varies linearly with both of $\mathrm{P}_{2} \mathrm{O}_{5}$ and $\mathrm{WO}_{3}$ contents. At high temperatures glass becomes a viscous 'liquid' and has a high surface tension. On a $\mathrm{g}$-carbon substrate, the forces of the surface tension are balanced according to Young-Dupre's equation: ${ }^{29,30}$

$$
\cos \theta=\frac{\gamma_{s}-\gamma_{S L}}{\gamma_{L}}
$$

where $\gamma_{s}, \gamma_{L}$, and $\gamma_{S L}$ are the surface tension of the substrate, liquid, and the interface tension between the liquid and the substrate, respectively. From Eq. (3), larger surface tension of the glass melt increases the contact angle $\theta$. The results shown in Fig. 4 suggest that the surface tension of the TBSN system is increased by addition of $\mathrm{P}_{2} \mathrm{O}_{5}$ and $\mathrm{WO}_{3}$.

Figure 5 shows (a) OM and (b) SEM images of the TBSN-4W-16P glass particle. Figure 5 (a) is the side-view, and Fig. 5 (b) is the top-view of the particle. All of the TBSN-4W-16P glass particles possess a smooth surface, high sphericity with large contact angle, and optical transparency. High sphericity of the particle surface shown in Fig. 5 (a) reveals that the effect of gravity to asphericity is small, and the surface tension of the melt determines the shape of the particle in the micrometer-size region. Figure 6 shows the plot of the contact angle $\theta$ against the diameter of the $\mu$ SSs. $\theta$ increased with decreasing the diameter, and $\theta=180^{\circ}$, i.e. microsphere with no truncated area, was achieved when the diameter was smaller than $40 \mu \mathrm{m}$.

Figure 7 (a) shows a Raman spectrum of TBSN-4W-16P glass. The spectrum was corrected for intensity by Eq. (2). The broad Raman band, centered at $780 \mathrm{~cm}^{-1}$ with $360 \mathrm{~cm}^{-1}$ full-width-half-maximum (FWHM), was observed. Figure 7 (b) shows the Raman spectrum of a TBSN-4W-16P $\mu \mathrm{SS}$ with a diameter of $37 \mu \mathrm{m}$. Periodic sharp peaks attributed to WGM resonances are observed. These peaks were observed even when pumped at the lowest power of $5 \mathrm{~mW}$, and increased in intensity with increasing pumping power.

According to the Lorenz-Mie theory, a mode spacing $\Delta v$ is known to correlate with the diameter of the microsphere $d$ and refractive index $n$ as follows: ${ }^{28}$

$$
\Delta v \approx \frac{1}{\pi d} \cdot \frac{\tan ^{-1}\left(n^{2}-1\right)^{1 / 2}}{\left(n^{2}-1\right)^{1 / 2}} .
$$




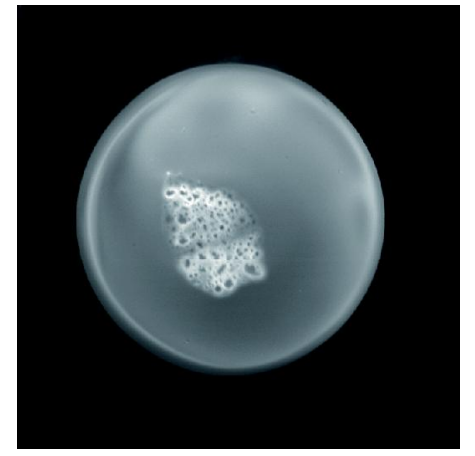

TBSN-OW-OP

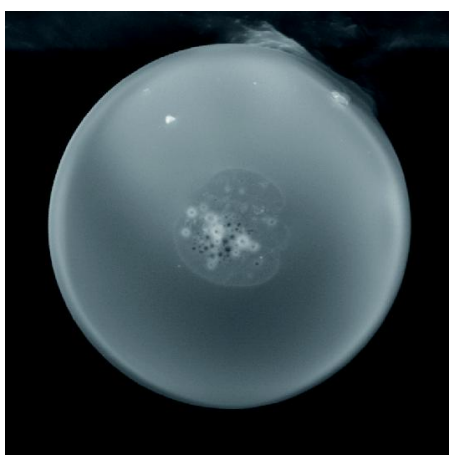

TBSN-0W-16P

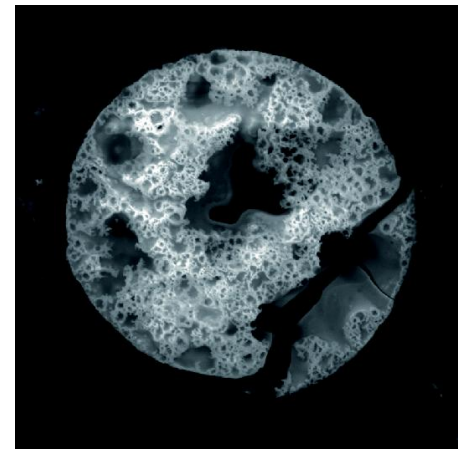

TBSN-4W-0P

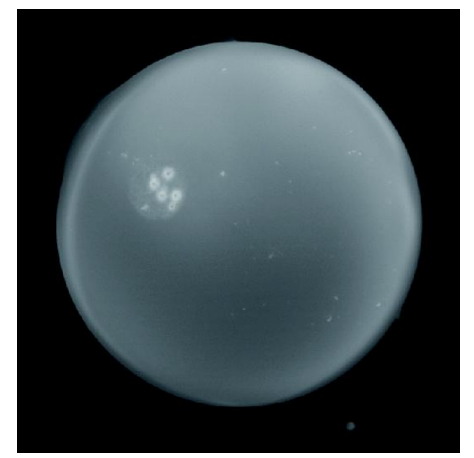

TBSN-2W-16P

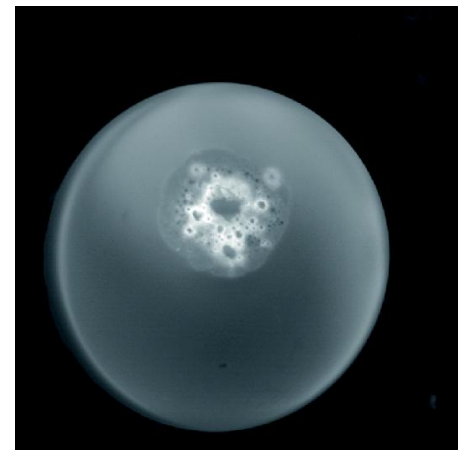

TBSN-4W-8P

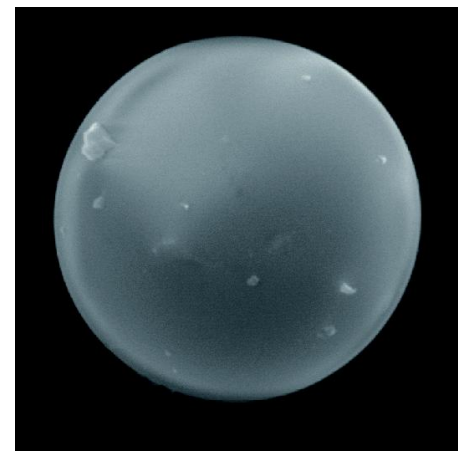

TBSN-4W-16P

Figure 3. SEM images of the bottom-side of the obtained glass particles with the diameter of about $35 \mu \mathrm{m}$.

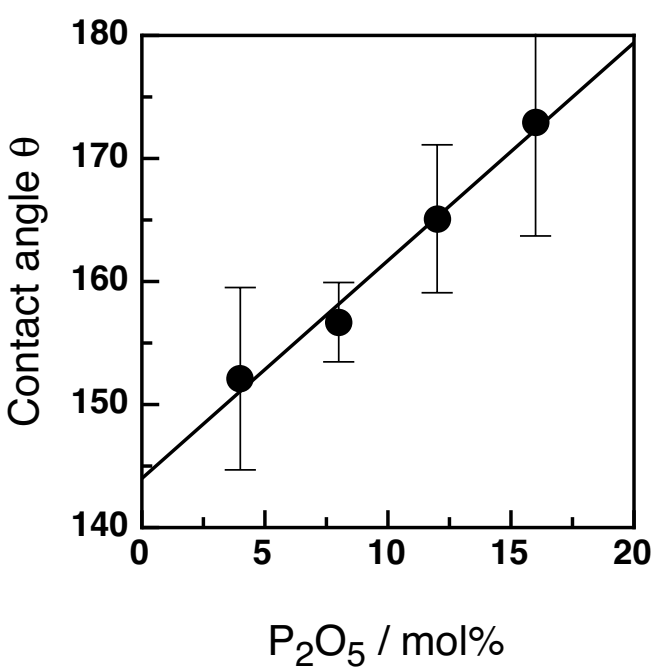

(a)

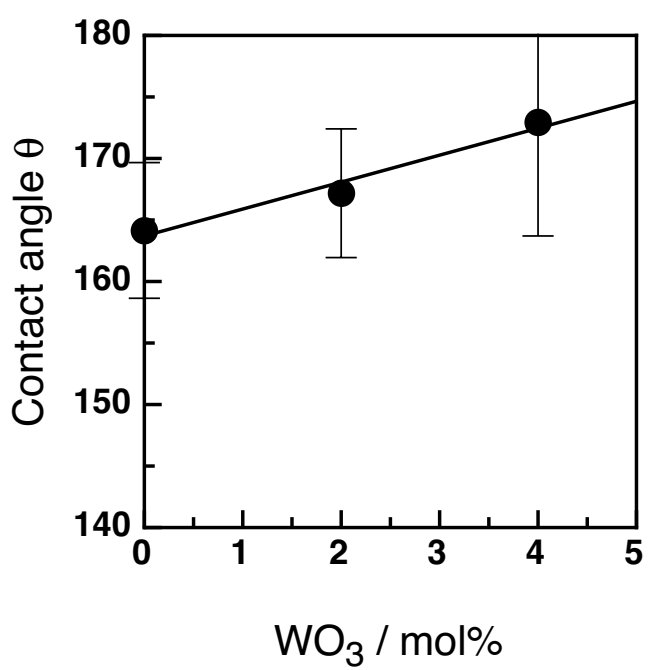

(b)

Figure 4. Variation of the contact-angle $\theta$ against the (a) $\mathrm{P}_{2} \mathrm{O}_{5}$ and (b) $\mathrm{WO}_{3}$ contents. The compositions of the samples are (a) TBSN$4 \mathrm{~W}-x \mathrm{P}(x=0 \sim 16)$ and (b) TBSN- $x \mathrm{~W}-16 \mathrm{P}(x=0 \sim 4)$, respectively. 


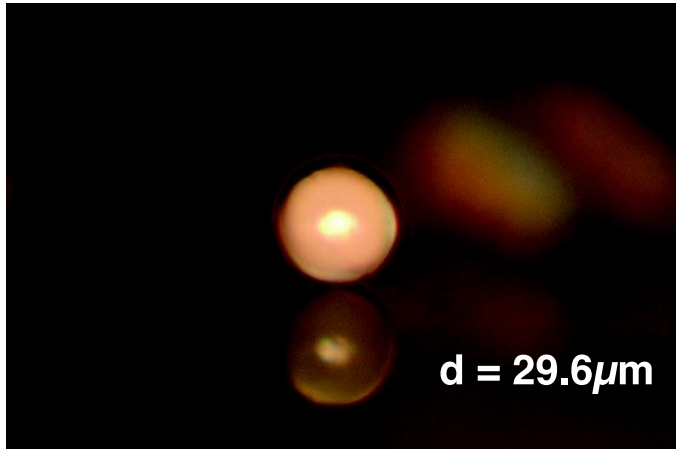

(a)

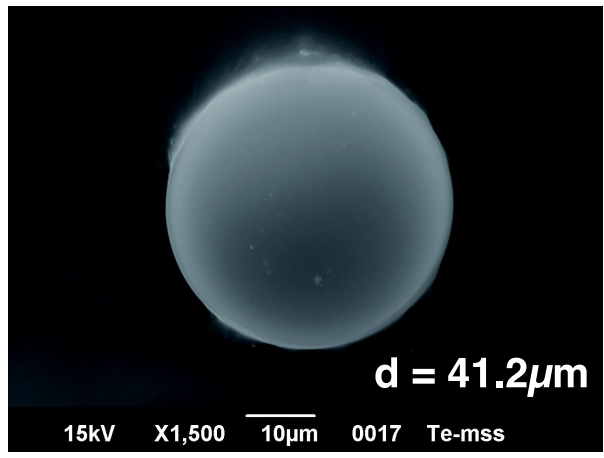

(b)

Figure 5. (a) Optical microscope and (b) SEM images of TBSN-4W-16P $\mu$ SSs. (a) is the side-view, and (b) is the top-view of the $\mu$ SS.

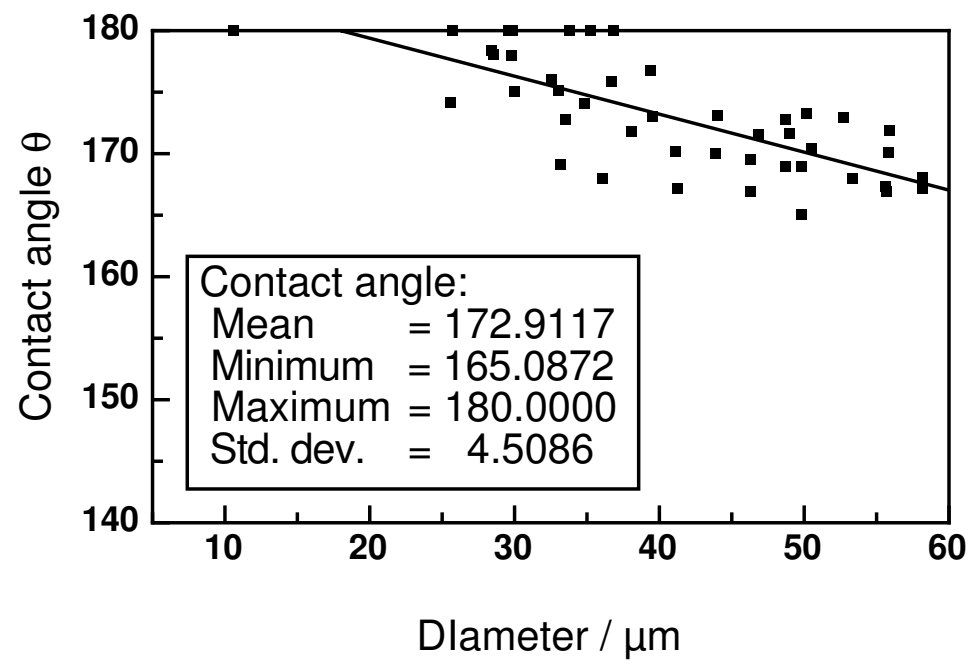

Figure 6. Contact angle $\theta$ against the diameter of the TBSN-4W-16P $\mu$ SSs.

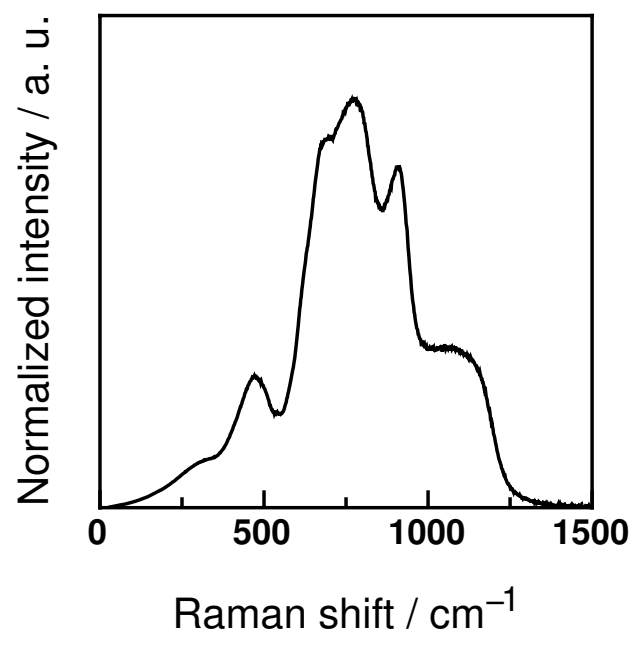

(a)

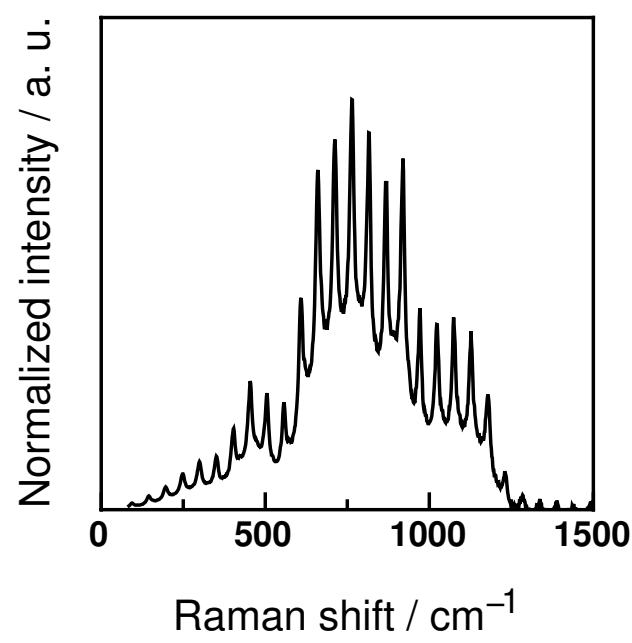

(b)

Figure 7. (a) Raman scattering spectra of the TBSN-4W-16P bulk glass and (b) WGM resonance spectrum of the TBSN-4W-16P $\mu$ SS. 
The calculated $\Delta v$ using the values of $n=1.98$ and $d=37 \mu \mathrm{m}$ is $51 \mathrm{~cm}^{-1}$, and it corresponds well with measured $\Delta v=$ $52 \mathrm{~cm}^{-1}$. The $Q$ values of these peaks were estimated from the equation, $Q=\omega_{0} / \Delta \omega$, where $\omega_{0}$ and $\Delta \omega$ is the center frequency and the FWHM of the resonance peak, respectively. From the spectrum in Fig. 7 (b), $Q$ was calculated to $5 \times 10^{3}$. Therefore, the prepared TBSN-4W-16P $\mu$ SSs were considered to have the sufficiently spherical shape and act as an efficient WGM resonator.

\section{SUMMARY}

Tellurite glass micro-superspheres (Te- $\mu \mathrm{SSs}$ ) were prepared by the StM technique, and their WGM resonances have been investigated as the first trial to realize an ultra-broadband Raman resonator. Micrometer-sized tellurite glass particles were melted on a glassy-carbon substrate with a surface of optical grade and cooled to room temperature. Resultant Te- $\mu \mathrm{SS}$ possesses a super-spherical shape with high optical transparency. The size of the partly truncated area, resulting from the contact between the surface and the substrate, can be controlled by the composition of the glass, and a microsphere with no truncated area was achieved for a glass with $56 \mathrm{TeO}_{2}-3.5 \mathrm{BaO}-10.5 \mathrm{SrO}-8 \mathrm{Nb}_{2} \mathrm{O}_{5}-4 \mathrm{WO}_{3}-16 \mathrm{P}_{2} \mathrm{O}_{5}(\mathrm{TBSN}-4 \mathrm{~W}-16 \mathrm{P})$ composition. The TBSN-4W-16P $\mu \mathrm{SS}$ was excited at $532 \mathrm{~nm}$, and the WGM resonance emission attributed to broad

Raman scattering of the glass itself was observed. The $Q$ value of the $\mu \mathrm{SS}$ was $\approx 5 \times 10^{3}$ and the prepared $\mu \mathrm{SSs}$ possess the sufficiently spherical shape and also acted as an efficient WGM resonator. These results predict that the Te- $\mu \mathrm{SS}$ has a potential for the novel broadband Raman lasers.

\subsection{Acknowledgments}

This work was supported in part by MEXT, the Private University High-Tech Research Center Program (2006-2010).

\section{REFERENCES}

1. W. J. Miniscalco, "Erbium-doped glasses for fiber amplifiers at 1500 nm," IEEE J. Lightwave Technol. 9, p. 234-250, 1991.

2. M. Semenkoff, M. Guibert, D. Ronarc'h, Y. Sorel, and J. F. Kerdiles, "Improvement of gain flatness of optical fluoride fiber amplifiers for multiwavelength transmission," J. Non-Cryst. Solids 184, pp. 240-243, 1995.

3. Y. Ohishi, "Ultrabroadband optical amplifiers for WDM," in Proc. of SPIE 5246, pp. 163-173, 2003.

4. M. N. Islam, Raman Amplification for Telecommunications, ch. 1, pp. 1-34. Springer-Verlag, New York, 2004.

5. A. Mori, H. Masuda, K. Shikano, and M. Shimizu, "Ultra-wide-band tellurite-based fiber Raman amplifier," J. Lightwave Technol. 21, pp. 1300-1306, 2003.

6. R. Stegeman, L. Jankovic, H. Kim, C. Rivero, G. Stegeman, K. Richardson, P. Delfyett, Y. Guo, A. Schulte, and T. Cardinal, "Tellurite glasses with peak absolute Raman gain coefficients up to 30 times that of fused silica," Opt. Lett. 28, pp. 1126-1128, 2003.

7. G. S. Murugan, T. Suzuki, and Y. Ohishi, "Tellurite glasses for ultrabroadband fiber Raman amplifiers," Appl. Phys. Lett. 86, pp. 161109-1-161109-3, 2005.

8. V. G. Plotnichenko, V. O. Sokolov, V. V. Koltashev, E. M. Dianov, I. A. Grishin, and M. F. Churbanov, "Raman band intensities of tellurite glasses," Opt. Lett. 30, pp. 1156-1158, 2005.

9. R. Stegeman, C. Rivero, K. Richardson, G. Stegeman, J. Peter Delfyett, Y. Guo, A. Pope, A. Schulte, T. Cardinal, P. Thomas, and J.-C. Champarnaud-Mesjard, "Raman gain measurements of thallium-tellurium oxide glasses," Opt. Express 13, pp. 1144-1149, 2005.

10. J. S. Wang, E. M. Vogel, and E. Snitzer, "Tellurite glass: a new candidate for fiber devices," Opt. Mater. 3, pp. 187203, 1994.

11. D. R. Ulrich, "Electrical and optical properties of glasses in bismuth trioxide-tellurium dioxide system," J. Am. Ceram. Soc. 47, pp. 595-596, 1964.

12. H. Bürger, K. Kneipp, H. Hobert, W. Vogel, V. Kozhukharov, and S. Neov, "Glass formation, properties and structure of glasses in the $\mathrm{TeO}_{2}-\mathrm{ZnO}$ system," J. Non-Cryst. Solids 151, pp. 134-142, 1992.

13. G. S. Murugan, T. Suzuki, Y. Ohishi, Y. Takahashi, Y. Benino, T. Fujiwara, and T. Komatsu, "Second harmonic generation in transparent surface crystallized glasses in the $\mathrm{BaO}-\mathrm{B}_{2} \mathrm{O}_{3}-\mathrm{TeO}_{2}$ system," Appl. Phys. Lett. 85, pp. 34053407, 2004. 
14. G. S. Murugan and Y. Ohishi, " $\mathrm{TeO}_{2}-\mathrm{BaO}-\mathrm{SrO}-\mathrm{Nb}_{2} \mathrm{O}_{5}$ glasses: A new glass system for waveguide devices applications," J. Non-Cryst. Solids 341, pp. 86-92, 2004.

15. G. S. Murugan and Y. Ohishi, "Raman spectroscopic studies of $\mathrm{TeO}_{2}-\mathrm{BaO}-\mathrm{SrO}-\mathrm{Nb}_{2} \mathrm{O}_{5}$ glasses: Structure - property correlations," J. Appl. Phys. 96, pp. 2437-2442, 2004.

16. R. Jose and Y. Ohishi, "Enhanced Raman gain coefficients and bandwidths in $\mathrm{P}_{2} \mathrm{O}_{5}$ and $\mathrm{WO}_{3}$ added tellurite glasses for Raman gain media," Appl. Phys. Lett. 89, pp. 121122-1 - 121122-3, 2006.

17. Y. Ohishi and R. Jose, "Raman scattering characteristics of $\mathrm{WO}_{3}$ and $\mathrm{P}_{2} \mathrm{O}_{5}$ doped TBSN glasses: a new gain medium for broadband fiber Raman amplifiers (invited paper)," in Proc. of SPIE 6389, pp. 638906-1 - 638906-13, 2006.

18. S. M. Spillane, T. J. Kippenberg, and K. J. Vahala, "Ultralow-threshold Raman laser using a spherical dielectric microcavity," Nature 415, pp. 621-623, 2002.

19. F. Lissillour, P. Féron, N. Dubreuil, P. Dupriez, and G. M. Stéphan, "Whispering-gallery mode Er-ZBLAN microlasers at 1.56 $\mu \mathrm{m}$," in Proc. of SPIE 3611, pp. 199-205, 1999.

20. T. Konishi, K. Soga, H. Inoue, and A. Makishima, "Synthesis and properties of glassy microcavities for morphologydependent resonances through liquid-liquid phase separation," J. Am. Ceram. Soc. 85, pp. 1151-1156, 52002.

21. S. Shibata, A. Tomizawa, H. Yoshikawa, T. Yano, and M. Yamane, "Preparation of spherical particles by vibrating orifice technique," in Proc. of SPIE 3943, pp. 112-119, 2000.

22. Y. Arai, T. Yano, and S. Shibata, "High refractive-index microspheres as optical cavity structure," J. of Sol-Gel Sci. and Tech. 32, pp. 189-194, 2004.

23. T. Kishi, S. Shibata, and T. Yano, "Preparation of micrometer size super spherical glasses for optical resonator," in Proc. of XX International Congress on Glass, O-14-022, (Kyoto, Japan), 2004.

24. T. Kishi, S. Shibata, and T. Yano, "Fabrication of SIL array of glass by surface-tension mold technique," in Proc. of SPIE 6126, pp. 61260P-1 - 61260P-8, 2006.

25. T. Yano, S. Shibata, and T. Kishi, "Fabrication of micrometer-size glass solid immersion lens," Appl. Phys. B 83, pp. 167-170, 2006.

26. T. Kishi, S. Shibata and T. Yano, "Fabrication of high-refractive-index glass micron-sized solid immersion lenses by a surface-tension mold technique" J. Non-Cryst. Solids, 2007, doi:10.1016/j.jnoncrysol.2007.07.065.

27. T. Kishi, S. Shibata and T. Yano, "Fabrication of micrometer-size solid immersion lens: composition dependence of wettability of substrate by glass melt" J. Non-Cryst. Solids, 2007, doi:10.1016/j.jnoncrysol.2007.08.051

28. S. C. Hill, Optical Effects Associated With Small Particles, ch. 1, pp. 3-61. World Scientific, Singapore, 1988.

29. T. Young, "An essay on the cohesion of fluids," Philos. Trans. Soc. London 95, p. 65, 1805.

30. A. Dupre, Theorie Mecanique de la Chaleur, p. 368. Gauthier-Villars, Paris, 1869. 